\title{
UNA APORTACION CRÍTICA SOBRE LA DOCTRINA DE RAWLS EN TORNO A LOS DERECHOS HUMANOS
}

\author{
A CRITICAL CONTRIBUTION ON RAWLS' HUMAN \\ RIGHTS DOCTRINE
}

\author{
FRANCISCO LA MONEDA DÍAZ \\ Universidad de Extremadura \\ Real Academia de Jurisprudencia y Legislación de Extremadura
}

\section{RESUMEN}

El presente artículo critica el relativismo de Rawls, quien considera que hay que cuestionarse el propio concepto de naturaleza humana, con sus consecuencias en relación con la ética y el fundamento de los derechos humanos, lo que lleva a un pluralismo absoluto. Frente a ello se propone no olvidar la evidencia del consenso de los derechos humanos como fundamento de universalidad ética y jurídica.

Palabras clave: John Rawls, derechos humanos, consenso, Declaración Universal de los Derechos Humanos

\section{ABSTRACT}

The present paper criticizes the relativism of Rawls, who considers that it is necessary to question the very concept of human nature, with its consequences in relation to ethics and the foundation of human rights, which leads to an absolute pluralism. In front 
of this he proposes not to forget the evidence of the consensus of human rights as foundation of ethical and juridical universality.

Keywords: John Rawls, human rights, consensus, Universal Declaration of Human Rights.

Quizás una de las más poderosas teorías de los últimos tiempos viene determinada por la denominada doctrina de las "razones públicas" y cuyo uno de sus máximos exponentes es precisamente el mencionado Rawls. Este autor, en el último tercio del siglo XX, nos traslada una concepción convencionalista de lo que será el concepto de justicia, entre otros, por tanto, estos principios no serían válidos por sí mismo sino en función del debate del que emanen sea justo. En realidad, no está estableciendo unos principios "verdaderos" sino "aceptados".

Este autor considera que la existencia humana flota en el misterio y que hay posibles explicaciones de la vida y del mundo, todas ellas aceptables, pero ninguna de ellas "abrumadoramente evidente". Es lo que él denomina "el hecho del pluralismo razonable". El problema consistirá en poner de acuerdo ${ }^{1}$ a esas sociedades plurales compuestas por personas que mantienen concepciones de la vida totalmente distintas. Se trata de buscar puntos comunes de encuentro ${ }^{2}$ entre personas con principios o creencias absolutamente distintos.

Aún partiendo de postulados evidentemente distintos, señala Joseph Ratzinger en su debate con Habermas, que la Iglesia de hoy en su diálogo con la sociedad secular y con otras comunidades de fe ha apelado a la razón común y ha buscado las bases para un entendimiento acerca de principios éticos en una sociedad

1 Robert Spaemann, Crítica de las utopías politicas (Pamplona: Eunsa, 1980), 191 ss.: “1) Existe un interés común a los hombres y cabe obtener un consenso sobre él a través de un diálogo racional. O sea, que existe la verdad en política y que cabe conocerla: el solo hecho de que aceptemos dialogar ya significa que reconocemos la existencia de intereses comunes. 2) El consenso fáctico de la mayoría no siempre es expresión de este interés común; el consenso no es racional a priori: la mayoría puede querer algo que no sea susceptible de ser aprobado por las personas razonables. El interés racional, en cambio, puede estar en cualquier hombre, aunque su postura sea minoritaria. 3) En principio, es posible que los hombres actúen guiados por un interés racional... Cuando Platón invoca la figura del rey-filósofo está señalando que debe mandar no simplemente aquél que impone su voluntad, sino quien es capaz de anticipar el consenso racional de todos".

2 Joaquín García-Huidobro, "Antígona: el descubrimiento del límite", Persona y Derecho 39 (1998): 85-106. Dice que el problema en Antígona es el problema de los límites. Pero hoy día se habla de límites, pero sin embargo se renuncia al fundamento de los límites. Este autor hace referencia en otros interesantes libros a la figura del Anillo de Giges, y al hermano de Platón en la República II. 
secular pluralista ${ }^{3}$. El propio Ratzinger en su discurso ante el parlamento federal alemán el 22 de septiembre de 2011 proclamó que para el desarrollo de la humanidad "los teólogos cristianos tomaran posición contra el derecho religioso que requiere la fe en la divinidad, y se pusieran de parte de la filosofia, reconociendo la razón y la naturaleza en su mutua relación como fuente jurídica válida para todos". En el discurso en Westminster Hall el 17 de septiembre de 2010 manifestó "que las normas objetivas para una acción justa de gobierno son accesibles a la razón, prescindiendo del contenido de la Revelación".

Bobbio ha señalado que el auténtico problema de los derechos humanos era el de su reconocimiento histórico más que el de su fundamentación. Rawls se ha ocupado de esta segunda tarea sobresalientemente para algunos autores ${ }^{4}$.

Pero Rawls, a diferencia de lo que Jacques Maritain consideraba como aquellas exigencias que derivan de la naturaleza humana, Rawls considera que hay que cuestionarse el propio concepto de naturaleza humana, es decir, si la naturaleza humana no es sino un conjunto de mecanismo inertes y azares bioquímicos ${ }^{5}$. En ese caso no podría derivarse ninguna conclusión de contenido ético. Un paso más delante de esta teoría que niega la existencia de una exigencia dentro de la naturaleza humana, sería la conclusión de que lo único que puede ponerse como denominador común entre la pluralidad de pueblos, civilizaciones, naciones o culturas es "aquello que se pueda esperar razonablemente que sea aceptado por todos los ciudadanos a la luz de principios e ideales de su razón humana común"6. Esta visión tiene como clara tentación la posibilidad de que se acuda a meras cuestiones de estadística o elevar a categoría de derechos los meros deseos o caprichos que sean o aquellos que mayoritariamente puedan vencer en ciertas encuestas. Ello si obviar la posible previa labor ideológica por parte de distintos movimientos, grupos, confesiones, partidos, prensa, lobbies, etc. Es decir, esta absoluta neutralidad, negadora del clásico fundamento de la naturaleza humana nos dejaría al albur de los grandes movimientos de los poderes económicos o emporios ideológicos que a su vez puedan movilizar campañas tendentes al reconocimiento y aceptación mayoritarios de nuevas concepciones, principios, directrices o la nueva definición de derechos. No será fácil

3 Joseph Ratzinger, "Posicionamiento en la discusión sobre las bases morales del estado liberal”. Dispopnible en http://cedes.iesp.uerj.br/PDF/06abril/anexo\%20IV\%20dossie.pdf

4 Julián Sauquillo, "De la abstracción al encarnamiento: La Filosofía Jurídica de Rawls", Isegoría 31 (2004): 267-273. Sobre los Derechos Humanos y el Derecho de Gentes, puede leerse entro otros muchos, cfr. Daniel Loewe, "Los derechos humanos y el derecho de gentes de John Rawls", Episteme NS 29/2 (2009): 19-40.

5 Ana Marta González, "El fundamento de la ley natural", en En busca de una ética universal: un nuevo modo de ver la ley natural. Documento de la Comisión Teológica Internacional y comentarios, ed. por Tomás Trigo (Pamplona: Eunsa, 2010), 147-166.

6 John Rawls, Political Liberalism (New York : Columbia University Press, 1993), 136. 
establecer unos principios comunes totalmente asépticos entre miles de millones de creyentes en lo sobrenatural y entre otros que nada creen al respecto, pues la concepción del hombre de unos y otros, y su fundamento último, va a determinar el contenido de esos principios o común denominador. Pero lo que ha de defenderse es que tanto una visión como otra son absolutamente aceptables, por tanto, no deberá imponerse ninguna de ellas sobre la otra, intentando buscar el punto de encuentro con criterios de razonabilidad y sin perder de vista que pueden alcanzarse visiones objetivas con este método, aunque de verdaderos mínimos, sin obviar en ningún caso una premisa a tener en cuenta en esta compleja apuesta por alcanzar el mínimo exigido. Nos estamos refiriendo al concepto, a la función, al desarrollo y a la visión que del ser humano se ha tenido desde los tiempos iniciales de los que tenemos conocimiento del ser humano sobre la tierra hasta la fecha. Es decir, por mucho que queramos y busquemos la asepsia antropológica y filosófica a fin de alcanzar escrupulosamente unos mínimos puntos de encuentro, en ese trayecto, no podrán obviarse las únicas concepciones conocidas del ser a lo largo de los siglos, como única (aunque múltiple y diversa) realidad empírica cognoscible frente a concepciones apenas desarrolladas e incipientes de que el ser humano no es más que una suma de células en la que tienen lugar químicas reacciones. Esto último es un hecho, pero un hecho primario y básico y que por sí solo no explica el hecho de la conciencia o la aparición en el hombre de ideas como el altruismo o la solidaridad. Reconocemos que la doctrina de las razones públicas, como el imán de los principios básicos sobre el que existirá universal consenso, debe estar abstraído de puntuales o concretas referencias a ideologías, filosofias o religiones (que hasta el mismo Ratzinger apoya). Pero esta doctrina no se ha desarrollado para una sociedad ideal, etérea o imaginaria, sino para un mundo concreto que cuenta con una notoria historia. Algo tan sencillo como excluir aquellas medidas, acciones o hechos que han provocado la extinción de seres humanos (aunque sea un argumento meramente numérico o estadístico) ha de ser recogido como negativo y nocivo, por lo que la experiencia del ser humano sobre la Tierra deberá ser tenida en cuenta como experiencia vital, capaz de legislar por si misma qué derechos o valores han de ser reconocidos y promovidos para evitar aquellos sucesos que por las circunstancias que fueran, provocaron la extinción, el dolor o el sufrimiento objetivo de seres humanos (algunos dirán que también el concepto de sufrimiento de relativo). Si relativizamos todo y nos cuestionamos los últimos fundamentos de cualquier concepto o idea, acabaremos recorriendo el camino, deshaciendo el trabajo del camino recorrido. No se puede estar permanentemente viendo "a través de" y así sucesivamente ir cuestionando la idea que se encuentra detrás, y de la que existe aún detrás de esa y así, sucesivamente. Como dice Lewis "es inútil intentar ver a través de los principios últimos. Si uno trata de ver a través de todo, entonces todo es transparente. Pero un mundo totalmente transparente es un mundo invisible. "Ver a través de" todas 
las cosas es lo mismo que no ver nada". El mismo nos habla que existe algo común a todas las culturas (hinduismo, budismo, cristianismo) que es la doctrina del valor objetivo, la convicción de que ciertas actitudes son realmente verdaderas y otras realmente falsas respecto a lo que es el universo y a lo que somos nosotros ${ }^{7}$

Sí parecen un denominador común en todo tiempo, civilización y pueblo que el sufrimiento, la marginación, la persecución y el homicidio de seres humanos es algo objetivamente deleznable o negativo, aún abstrayéndonos de concepciones religiosas o ideológicas de cualquier clase. Podríamos decir que es aquello sobre lo que existe práctica unanimidad de la raza humana, algo que de por sí ya supone un enorme avance para la búsqueda de ese denominador común, un criterio de base absolutamente fundamental para centrar el foco del problema que tratamos de desentrañar. Ese "consenso" sobre lo que incuestionable, histórica, común y estadísticamente es contrario a cualquier concepción filosófica, religiosa o ideológica del ser humano, entendemos que es el mayor fundamento a sensu contrario de la que podemos partir. Las teorías y doctrinas cualquiera que sea su procedencia, que busquen la mayor neutralidad o asepsia en la búsqueda del punto intermedio, no podrá oponer a esta teoría ninguna objeción o contaminación iusnaturalista o de cualquier otra índole, pues lo que una parte no puede desconocer ni desplazar ni ignorar es el contexto del todo, sin el que esa parte quedaría vacía de contenido. Es decir, el ser humano aún en una visión lo más reduccionista posible del propio ser como mero animal o como casual conjunción de reacciones fisicobioquímicas, no puede dejar de lado, en su riguroso y escrupuloso análisis, la única trayectoria conocida de ese ser sobre la faz de la tierra. Igualmente, a este análisis sólo habrá que añadir un consenso actual y secular sobre el deseo abrumadoramente (por no decir casi unánime) por supervivir o el deseo de su sobrevivencia. Tal vez, en la línea del consenso que recogía Bobbio y otros que hemos mencionado, es donde sin duda tenemos que movernos para, aparte de las importantes disquisiciones filosóficas, entender que los ciudadanos del mundo de hoy, encontraron hace décadas un amplio consenso en la consideración de los derechos humanos. Por supuesto que, sin duda, aquellas doctrinas filosóficas que nacieron en Grecia y se desarrollaron por diversos pensadores a lo largo de los siglos, y en las que ocupa un lugar destacado la Escuela de Salamanca, sirvieron de esencial sustrato para la elaboración de aquellas declaraciones y forjó paulatinamente el espíritu necesario para consecución de tal consenso.

Creemos que la Declaración Universal de Derechos Humanos de 1948, es la plasmación de aquél necesario consenso mundial. La génesis de aquel singular, difícil y espectacular entente, ha sido descrito y narrado con particular maestría

7 Clive S. Lewis, La abolición del hombre (Madrid: Encuentro, 2008), 23. 
por la norteamericana Mary Ann Glendon ${ }^{8}$ que accediendo a los diarios, memorias y documentación desclasificada ha contado los entresijos de los verdaderos artífices de varias nacionalidades que dejaron lo mejor de sí mismos para lograr tan universal acuerdo. Lo que hace enormemente peculiar a esta declaración es comprobar a través de este magnífico trabajo cómo aquella carta magna no fue el mero resultado de influyentes diplomáticos europeos, filósofos cristianos o de la aspiración de filántropos occidentales. El chino Peng-chun, el juez francés y premio Nobel de la Paz, René Cassin, el filósofo libanés Charles Malik, y Eleonor Roosevelt fueron los cuatro más destacados actores de aquella hazaña. Peng-Chun sostuvo, por ejemplo, que la idea de la fraternidad era muy anterior en su cultura (que la denominaban "mentalidad de dos personas") a la Ilustración francesa.

En cualquier caso, lo importante es, como se ha dicho, que una idea sea buena y en beneficio del desarrollo de la humanidad y no a quién se le ocurrió primero. "El argumento de la singularidad cultural no puede superar la realidad de que compartimos los atributos más elementales: ... todos sentimos dolor, hambre y cientos de formas de perversión... la idea de derechos humanos universales comparte el reconocimiento de una humanidad común y ofrece una pequeña solución para enfrentar sus miserias"".

El primer artículo de la Declaración que establece que "Todos los seres humanos nacen libres e iguales en dignidad y derechos y dotados como están de razón y conciencia, deben comportarse fraternalmente los unos con los otros", responde al primer Considerando de la misma carta que parte de la base del reconocimiento de la dignidad intrínseca de los derechos iguales e inalienables de todos los miembros de la familia humana, que son la base de la libertad, la justicia y la paz del mundo. Es decir, las naciones del mundo se han puesto de acuerdo en la aceptación explícita de unos mínimos reconocimientos a todas las personas, con independencia de sus religiones, razas, nacionalidades, sexos, colores o idiomas, estableciendo un común denominador universal de contenido idéntico, alcanzado con el consenso de divergentes culturas, filosofías, religiones, o ideologías (que no deslegitima Rawls) y con la inequívoca voluntad de no meramente declarar unos principios programáticos sino de exigir su respeto, consolidando con ello un cuerpo firme y una doctrina clara y contundente para todos los habitantes de la Tierra. Con ello, la humanidad, contará a partir de 1948 con la concreción de lo que venía considerándose una vieja disquisición

8 Mary Ann Glendon, Un mundo nuevo. Eleanor Roosevelt y la Declaración Universal de Derechos Humanos (México: Universidad Panamericana, 2011), quien a lo largo de 428 páginas relata los antecedentes de la Declaración y los debates internos de los intervinientes.

9 Daniel S. Lev, mencionado por Glendon, Un mundo nuevo..., 325. 
filosófica. Seguirá habiendo lugar, no obstante, como veremos, a dialécticas filosóficas sobre el fundamento de tales consensos.

Podríamos decir que esta declaración conformaría ese núcleo de principios comúnmente aceptados. Esto nos llevaría a la consideración de que estamos ante un nuevo positivismo jurídico y cuyo fundamento no sería otro que la propia declaración referida. Pues bien, sea como fuere, Derecho Natural o Positivo, es preceptiva e imperativa la referida Declaración tanto para los positivistas como para los iusnaturalistas.

Es precisamente en este marco donde entendemos que debe encuadrarse el desarrollo de los estudios, convenciones y reuniones que dieron lugar a la Declaración Universal de los Derechos Humanos de 1948.

\section{REFERENCIAS BIBLIOGRÁFICAS}

García-Huidobro Joaquín. "Antígona: el descubrimiento del límite". Persona y Derecho 39 (1998): 85-106.

Glendon, Mary Ann. Un mundo nuevo. Eleanor Roosevelt y la Declaración Universal de Derechos Humanos. México: Universidad Panamericana, 2011.

González, Ana Marta. "El fundamento de la ley natural". En En busca de una ética universal: un nuevo modo de ver la ley natural. Documento de la Comisión Teológica Internacional y comentarios, editado por Tomás Trigo, 147-166. Pamplona: Eunsa, 2010.

Lewis, Clive S. La abolición del hombre. Madrid: Encuentro, 2008.

Loewe, Daniel. "Los derechos humanos y el derecho de gentes de John Rawls". Episteme NS 29/2 (2009): 19-40.

Ratzinger, Joseph. "Posicionamiento en la discusión sobre las bases morales del estado liberal". Dispopnible en http://cedes.iesp.uerj.br/PDF/06abril/ anexo\%20IV\%20dossie.pdf,

Rawls, John. Political Liberalism. New York : Columbia University Press, 1993. Sauquillo, Julián. "De la abstracción al encarnamiento: La Filosofía Jurídica de Rawls". Isegoría 31 (2004): 267-273.

Spaemann, Robert. Crítica de las utopías políticas. Pamplona: Eunsa, 1980.

Francisco La Moneda Díaz

Facultad de Económicas

Universidad de Extremadura

Avda. Elvas $\mathrm{s} / \mathrm{n}$

06006 Badajoz (España)

https://orcid.org/0000-0002-3010-5511 
